\title{
An Examination of Paraoxonase 1 Gene Polymorphism in Cases of Chronic Otitis Media
}

\author{
Kasım Durmuș ${ }^{1}$, Hande Küçük Kurtulgan², Adem Bora', Malik Ejder Yıldırım², Emine Elif Altuntaș ${ }^{1}$ \\ 1 Department of Otolaryngology, Faculty of Medicine, Sivas Cumhuriyet University, Sivas, Turkey \\ 2 Department of Medical Genetics, Faculty of Medicine, Sivas Cumhuriyet University, Sivas, Turkey \\ Kasım Durmuş, ORCID: 0000-0002-0447-1665 \\ Hande Küçük Kurtulgan, ORCID: 0000-0001-9172-3244 \\ Adem Bora, ORCID: 0000-0002-5036-0595 \\ Malik Ejder Ylldirım, ORCID: 0000-0003-4386-1583 \\ Emine Elif Altuntaş, ORCID: 0000-0003-4503-3730
}

\begin{abstract}
Objective: Chronic otitis media (COM) is a multifactorial disorder, the pathogenesis of which has yet to be fully elucidated. Numerous aetiological factors, including genetics, eustachian tube dysfunction, autoimmunity, infection, osteoclastic activity, cytokines, endotoxins, and products of lipid peroxidation resulting from oxidative stress, have been proposed to explain the chronic inflammation which lies at the heart of the disorder. The aim of this study is to investigate a possible relationship between the pathogenesis of COM and polymorphism within the paraoxonase 1 (PON1) gene.
\end{abstract}

Methods: We investigated 49 patients admitted to the Otorhinolaryngology Department of Cumhuriyet University and diagnosed with COM between September and November 2017. The control group consisted of 51 healthy individuals. Polymerase chain reaction (PCR) - restriction fragment length polymorphism (RFLP) methods were used to genotype the PON1 Q192R (rs662) polymorphism.
Results: When the case and control groups were compared in terms of the existence of PON1 (Q192) polymorphism, there was no statistically significant difference between the groups $(p=0.166, p>0.05)$. When intergroup comparison was performed on the type of PON1 (Q192) polymorphism, there was also no statistically significant difference $(p=0.261, p>0.05)$.

Conclusion: The present study is the first known study in which PON1 polymorphism has been examined in cases of COM. The results of our study failed to indicate a statistically significant relationship between PON1 polymorphism and COM. However, it is important to note that the higher rate of 192RR polymorphism within the control group may indicate a protective effect in COM.

Keywords: Otitis media, oxidative stress, paraoxonase-1, genetic polymorphism. 


\section{Introduction}

Chronic otitis media (COM) involves infection by aerobic or anaerobic microorganisms. Characteristically, tympanic membrane perforation occurs, indicating the change from a pattern of acute to chronic inflammation. A discharge lasting for more than three months is also present. ${ }^{[1]}$ Even though it is accepted that COM is multifactorial in aetiology, the precise pathogenic mechanism has yet to be fully elucidated..$^{[2-4]}$ Numerous aetiological factors, including genetics, eustachian tube dysfunction, autoimmunity, infection, osteoclastic activity, cytokine profile alterations, the presence of endotoxins, and products of lipid peroxidation resulting from oxidative stress, have been proposed to explain the chronic inflammation which lies at the heart of the disorder. ${ }^{[5-12]}$

Paraoxonase 1 (PON1) is a member of the paraoxonase (PON) enzyme family (PON1-3), synthesised in the liver, but also found in the circulation. ${ }^{[13]}$ PON1 combines with high density lipoprotein (HDL) in serum. Some of the anti-oxidative and anti-inflammatory effects associated with HDL have been attributed to the presence of PON1. ${ }^{[14]}$ PON1 hydrolyses lipid peroxides in lipoproteins and thus prevents further oxidation of low density lipoprotein (LDL) and HDL. ${ }^{[15]}$ Various studies have indicated that PON prevents oxidative stress by inhibiting the oxidation of lipids in the cell membrane induced by free oxygen radicals produced by acute and chronic inflammation. ${ }^{[16]}$

The PON1 gene codes for a protein consisting of 354 amino acids and is located at the q21.3 - q22.1 site of chromosome $7{ }^{[17]} \mathrm{PON}$ activity exhibits major differences between individuals. These differences are partially associated with genetic polymorphism. Two common polymorphisms in the coding region of the PON1 gene are known - M55L and Q192R. ${ }^{[18,19]}$

Various polymorphisms within the PON1 gene have been found to be associated with a number of diseases, via changes in enzymatic activity and serum level, notably polycystic ovary syndrome, diabetes mellitus, hypertension, anti-phospholipid syndrome, systemic lupus erythematosus, coronary artery disease, rheumatoid arthritis, renal failure, and macular degeneration. ${ }^{[19-23]}$ Chronic inflammation is a feature of many such diseases, including, of course, COM.

Although it has been suggested that oxidative stress is likely to play a role in the pathogenesis of COM, how this could occur has not yet been definitively established. A literature search reveals two studies, one by Baysal et al ${ }^{[12]}$ and one by Turan et al ${ }^{[24]}$, in which the relationship between PON and COM has been investigated. Both studies evaluated the enzymatic activity of circulating PON in individuals with COM. No study investigating PON1 gene polymorphism was found in the literature. Therefore, the aim of our study was to investigate whether or not there was a relationship between the pathogenesis of the disease and the existence of PON1 genetic polymorphism in cases of COM.

\section{Materials and Methods}

\section{Population investigated}

In this study, for the COM cases group, we used 49 patients who had been admitted to the Otorhinolaryngology Department of Cumhuriyet University and diagnosed with COM between September and November 2017. The control group comprised 51 healthy individuals without ear problems or known chronic systemic disease, who were matched for age and sex, unrelated to each other, and had volunteered for the study.

The following exclusion criteria were used: previous history of tympanomastoid surgery; learning disability; any known genetic disorder; use of medications known to be ototoxic; congenital hearing loss; chronic systemic disease; or cranial radiotherapy. COM duration was between 1 year and 40 years and without periodic disease-free intervals. The inclusion criteria for individuals in the control group were as follows; having a pure tone mean threshold better than $20 \mathrm{~dB}$; a healthy tympanic membrane on otoscopic examination; no findings on examination suspicious of active middle ear infection; no previous history of otological disease or surgery; no congenital cochlear malformation, mechanical trauma, or neurological disease known to cause loss of hearing; no vascular disease, or history of systemic disease occasioning the intake of any ototoxic drugs within the preceding month; no hypertension, hypothyroidism, hepatic or renal failure; no infection known to lead to loss of hearing, e.g. syphilis; not having had chemotherapy or radiotherapy for any reason within the preceding month. A general physical examination plus an audiological evaluation were carried out and blood samples collected for genetic analysis in all participants.

All patients gave prior written informed consent before participating in the study, which was approved by the Ethical Committee of Cumhuriyet University. The study was conducted in accordance with the principles in the Declaration of Helsinki. 


\section{Collection of Blood Samples and DNA Extraction}

A sample of peripheral venous blood of volume $5 \mathrm{ml}$ was drawn from all participants and placed into tubes containing ethylenediaminetetraacetic acid (EDTA), with the intention to identify the presence of the Q192R (rs662) polymorphism within the PON1 gene. Genomic DNA was extracted from $200 \mu \mathrm{L}$ of this peripheral blood using the QIAamp DNA mini kit (Qiagen, Hilden, Germany). The purity and concentration of the DNA obtained were measured using the NanoDrop ND-1000 spectrophotometer (Thermo Fisher Scientific, Waltham, MA, USA).

\section{Genotypic Analysis}

Polymerase chain reaction (PCR) - restriction fragment length polymorphism (RFLP) methods were used to genotype the PON1 Q192R (rs662) polymorphism. Forward TAATCCTGTAATGTTCAATACCTTCAC and reverse AGAGTTCACATACTTGCCATCG primers were utilised for DNA amplification.

The PCR was performed in a total reaction volume of $25 \mu \mathrm{L}$ including $1 \mu \mathrm{L}$ genomic DNA, $12.5 \mu \mathrm{L} 2 \times$ PCR master mix, $1 \mu \mathrm{L}$ each of the forward and reverse primers, and $9.5 \mu \mathrm{L} \mathrm{dH} 2 \mathrm{O}$. The PCR conditions were: initial denatura-tion for $5 \mathrm{~min}$ at $95^{\circ} \mathrm{C}, 35$ cycles of $1 \mathrm{~min}$ at $95^{\circ}$ $\mathrm{C}, 1 \mathrm{~min}$ at $61^{\circ} \mathrm{C}$ and $1 \mathrm{~min}$ at $72^{\circ} \mathrm{C}$, followed by $10 \mathrm{~min}$ at $72^{\circ} \mathrm{C}$. En-zyme digestion was performed in a volume of 15 $\mu \mathrm{L}$ with $7 \mu \mathrm{L}$ of amplicon, $0.5 \mu \mathrm{L}$ of $\mathrm{MboI}$ restriction endonuclease, $2.5 \mu \mathrm{L}$ buffer and $5 \mu \mathrm{L}$ dH2O. The mixture was left for in-cubation overnight at $37^{\circ} \mathrm{C}$. Digestion products were run out on a $3 \%$ agarose gel (Bimax, Prona, $\mathrm{EU})$ containing ethidium bromide, at 100 Volts for $40 \mathrm{~min}$. The lengths of the fragments were QQ 165 and 109 bp, RR 137, 109, and 28 bp, QR 165, 137, 109, and 28 bp.

The SPSS (SPSS Inc., Chicago, IL) 23.0 software application was used to evaluation the data obtained from the study. In the statistical analysis, the level of significance was taken as 0.05 when applying a test of the difference between 2 mean scores of independent groups (Student's t-test), provided parametric test assumptions were fulfilled; the chi-square test and correlation analysis was used if the parametric test assumptions were not fulfilled.

\section{Results}

In this study, 49 patients with COM were compared with 51 healthy volunteers. The mean ages of the patients and the controls were $43.55 \pm 16.92$ ( $\min -\max : 12-72$ ) and $38.37 \pm 14.08$ ( $\min -\max : 18-80$ ) years, respectively $(p=0.099$, i.e. $p>0.05)$. A total of $47.9 \%(n=23)$ of the COM group and $41.2 \%(n=21)$ of the control group were female, whilst $52.1 \%(n=25)$ of the COM group and $58.8 \%$ $(n=30)$ of the control group were male $(p=0.500, p>0.05)$. The distribution of sex and age was similar between the two groups $(\mathrm{p}>0.05)$.

There was no statistically significant difference ( $p=0.166$, i.e. $p>0.05)$ in the prevalence of the PON1 Q192 polymorphism between the two groups (Table 1). When the groups were compared for the type of PON1 (Q192) polymorphism, likewise no difference existed at the level of statistical significance $(\mathrm{p}=0.261$, i.e. $\mathrm{p}>0.05)$ (Table 2$)$.

\begin{tabular}{|c|c|c|}
\hline & \multicolumn{2}{|c|}{ PON 1 (Q192 R) Polymorphism } \\
\hline & $\begin{array}{c}\text { Yes } \\
(\mathrm{QR+RR})\end{array}$ & $\begin{array}{c}\text { No } \\
\text { (QQ) }\end{array}$ \\
\hline Group СOM & $25(51 \%)$ & $24(49 \%)$ \\
\hline Group Control & $33(64.7 \%)$ & $18(35.3 \%)$ \\
\hline Total & $58(58 \%)$ & $42(42 \%)$ \\
\hline$p$ value & 0.294 & 0.355 \\
\hline
\end{tabular}

PON1: Paraoxonase 1; Q192 R: Gluthamine192 Arginene; QR: Heterozygous; RR: Mutated allel, homozygous; QQ: Wild allel; COM: Chronic otitis media

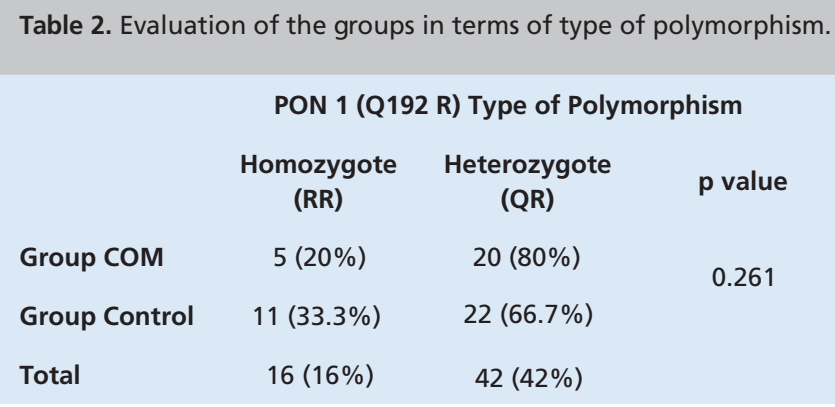

PON1: Paraoxonase 1, Q192 R: Gluthamine192 Arginene, RR: Mutated allel, homozygous, QR: Wild allel, COM: Chronic otitis media

\section{Discussion}

The study aimed to answer the question as to whether genetic polymorphism in the PON1 gene exerts any protective effect in COM, this being based on the hypothesis that oxidative stress plays an aetiological role in the formation of COM and that PON is known to lessen oxidative 
stress in other acute and chronic inflammatory conditions. Although the results of this study show that there was no statistical difference between cases and controls in terms of PON1 polymorphism, the fact that the homozygotic (RR) polymorphism was more prevalent in the control group should not be discounted.

PON is one of the most important antioxidant enzymes in humans. The PON1 enzyme found in human serum is a crucial protector against oxidative stress. Various studies have indicated that oxidative stress decreases the activity of PON1 and results in reduced PON1 expression in serum. ${ }^{[15,25]}$

Shigemi et al ${ }^{[26]}$ claim in their study that reactive oxygen species (ROS) are likely to be associated with COM. In studies conducted by Yilmaz et al ${ }^{[5]}$ and Yariktaş et al [27] on paediatric patients suffering from otitis media with effusion, serum levels of free oxygen radicals were discovered to be elevated secondary to middle ear inflammation. Indeed, even though there was some decrease in serum levels of free oxygen radicals following surgery, the levels failed to return to completely normal levels.

Despite the relationship between otological diseases, e.g. acute otitis media, otitis media with effusion, and tympanosclerosis with the oxidant-antioxidant system having been established, potential roles for oxidants and antioxidants in the pathogenesis of COM have not been well-delineated so far. There is a minimal number of studies about oxidant and antioxidant mechanisms in patients with COM extant in the literature. ${ }^{[1,6,12,24]}$ However, that a relationship between oxidative stress and COM exists is noteworthy.

Garça et al ${ }^{[1]}$ examined the levels of malondialdehyde, anti-oxidant catalase enzymes, superoxide dismutase and glutathione peroxidase in pathological tissue samples and serum showing mucosal inflammation in the middle ear and mastoid cells, with or without cholesteatoma. The results of this study indicate that oxidative stress plays a role in the pathogenesis of COM, with or without cholesteatoma, but may not reflect how severe the disease actually is.

Two studies of interest were identified from the Pubmed database using the keywords "otitis media" and "paraoxonase level". The first study identified was by Baysal et al ${ }^{[12]}$, in which the activity of serum PON enzyme in cases of COM (either with or without cholesteatoma) was investigated. The study revealed that there was a statistically significant difference between the markers of oxidative stress and the capacity of antioxidant enzymes between groups.
Serum PON activity was found to be significantly lower in cases with cholesteatoma $(154.05 \pm 40.10)$ than in either cases without cholesteatoma $(161.08 \pm 17.26)$ or a control group $(176.04 \pm 28.65)$. The study authors concluded that increased oxidative stress leads to increased levels of antioxidant enzymes unless the oxidative stress was severe, when antioxidant levels actually fell.

The second study identified was by Turan et al. ${ }^{[24]}$ The level of lipid hydroperoxide ( $\mathrm{LOOH}$ ) was investigated in this study in addition to the same parameters used by Baysal et al ${ }^{[12]}$ in their study. Turan et al ${ }^{[24]}$ discovered that serum $\mathrm{PON}$ and arylesterase activity was significantly lower, and the $\mathrm{LOOH}$ level higher, in patients with COM compared to individuals in their control group. They state that low serum PON1 activity may be considered an indicator of oxidant-antioxidant imbalance, claiming in addition that low serum PON1 activity may have an important role to play in the pathogenesis of COM. Furthermore, Turan et al ${ }^{[24]}$ claimed that the mechanism for reduced PON1 serum activity observed in patients with COM was not yet fully explained, but this reduction could be the result of increased lipid peroxidation, given the fact that oxidized lipids are known to inhibit the activity of PON1. Based on increased production of ROS during inflammation, increased inactivation of PON1 may explain the reduced serum PON1 activity observed. ${ }^{[15]}$

Agachan et al [28], in their study published in 2004, state that the genotypes PON1 M55L and Q192R had an important effect on serum PON activity in cases of diabetes mellitus. In our study, PON activity was found to be higher in RR homozygous individuals than in individuals with the genotypes QQ and QR. The PON1 192RR genotype was more frequent in the control group than the COM group, but this result was not statistically significant.

Our literature review did not identify any study investigating the relationship between PON polymorphism and COM, which could be compared with our results. To the best of our knowledge, our study is the first one on PON1 polymorphism in cases with COM. Our study suffers from two major limitations, namely the fact that serum PON level was not studied along with PON1 polymorphism and the number of cases involved was relatively low.

\section{Conclusion}

The results of this study do not indicate a statistically significant relationship between PON1 polymorphism and COM. However, it is important to note that the higher rate 
of 192RR polymorphism within the control group may indicate a protective effect in COM. This is an area that future research should address. Furthermore, a study evaluating both serum PON enzyme levels and PON1 polymorphism, featuring a higher number of cases would be a major contribution to the literature by further elucidating the role of oxidative stress in the pathogenesis of COM.

Acknowledgements: We would like to thank Selim Çam for his contributions to the statistical evaluation.

Ethics Committee Approval: All procedures performed were in accordance with the ethical standards of the Sivas Cumhuriyet University Clinical Research Ethics Committee (date 19.10.2017 and no. 2017-09/05).

\section{References}

1. Garça MF, Turan M, Avşar B, et al. The evaluation of oxidative stress in the serum and tissue specimens of patients with chronic otitis media. Clin Exp Otorhinolaryngol 2015;8:97-101.

2. Semaan MT, Megerian CA. The pathophysiology of cholesteatoma. Otolaryngol Clin North Am 2006;39:1143-59.

3. Louw L. Acquired cholesteatoma pathogenesis: stepwise explanations. J Laryngol Otol 2010;124:587-93.

4. Shibosawa E, Tsutsumi K, Takakuwa T, Takahashi S. Stromal expression of matrix metalloprotease-9 in middle ear cholesteatomas. Am J Otol 2000;21:621-4.

5. Yilmaz T, Kocan EG, Besler HT, Yilmaz G, Gursel B. The role of oxidants and antioxidants in otitis media with effusion in children. Otolaryngol Head Neck Surg 2004;131:797-803.

6. Karlidag T, Ilhan N, Kaygusuz I, Keleş E, Yalcin S. Comparison of free radicals and antioxidant enzymes in chronic otitis media with and without tympanosclerosis. Laryngoscope 2004;114:85-9.

7. Döner F, Delibas N, Dogru H, Yariktas M, Demirci M. The role of free oxygen radicals in experimental otitis media. J Basic Clin Physiol Pharmacol 2002;13:33-40.

8. Aktan B, Gundogdu C, Ucuncu H, Unal B, Sütbeyaz Y, Altas S. Anti-inflammatory effect of erythromycin on histamine-induced otitis media with effusion in guinea pigs. J Laryngol Otol 2004;118:97-101.

9. Hamzei M, Ventriglia $G$, Hagnia $M$, et al. Osteoclast stimulating and differentiating factors in human cholesteatoma. Laryngoscope 2003;113:436-42.

10. Chole RA, Faddis BT. Evidence for microbial biofilms in cholesteatomas. Arch Otolaryngol Head Neck Surg 2002;128:1129-33.

11. Peek FA, Huisman MA, Berckmans RJ, Sturk A, Van Loon J, Grote JJ. Lipopolysaccharide concentration and bone resorption in cholesteatoma. Otol Neurotol 2003;24:709-13.

12. Baysal E, Aksoy N, Kara F, et al. Oxidative stress in chronic otitis media.
Informed Consent: Informed consent was obtained from all individual participants included in the study.

Author Contributions: Designing the study - K.D., H.K.K., A.B., M.E.Y., E.E.A.; Collecting the data - K.D., H.K.K., A.B., M.E.Y.; Analysing the data - K.D., H.K.K., A.B., M.E.Y.; Writing the manuscript - K.D., H.K.K., E.E.A.; Confirming the accuracy of the data and the analyses - E.E.A.

Conflict of Interest: The authors have no conflicts of interest to declare.

Financial Disclosure: The authors declared that this study has received no financial support.

Eur Arch Otorhinolaryngol 2013;270:1203-8

13. Costa LG, Cole TB, Jarvik GP, Furlong CE. Functional genomic of the paraoxonase (PON1) polymorphisms: effects on pesticide sensitivity, cardiovascular disease, and drug metabolism. Annu Rev Med 2003;54:371-92.

14. Durrington PN, Mackness B, Mackness MI. Paraoxonase and atherosclerosis. Arterioscler Thromb Vasc Biol 2001;21:473-80.

15. Aviram M, Rosenblat M, Bisgaier CL, et al. Paraoxonase inhibits high density lipoprotein (HDL) oxidation and preserves its functions: a possible peroxidative role for paraoxonase. J Clin Invest 1998;101:1581-90.

16. Koc S, Aksoy N, Bilinc H, Duygu F, Uysal IÖ, Ekinci A. Paraoxonase and arylesterase activity and total oxidative/anti-oxidative status in patients with chronic adenotonsillitis. Int J Pediatr Otorhinolaryngol 2011;75:1364-7.

17. Mackness M, Mackness B. Human paraoxonase-1 (PON1): Gene structure and expression, promiscuous activities and multiple physiological roles. Gene 2015;567:12-21.

18. Sarandöl E, Dirican M, Eröz E, Kırhan E, Serdar Z, Uncu G. Serum paraoxonase and arylesterase activities throughout normal pregnancy. Nobel Med 2011;7:49-55.

19. Goswami B, Tayal D, Gupta N, Mallika V. Paraoxonase: a multifaceted biomolecule. Clin Chim Acta 2009;410:1-12.

20. Gu HF, Mou M, Liang ZG, Sun C, Ren XY, Xiao YB. The association between paraoxonase 1 gene polymorphisms and polycystic ovarian syndrome. Cell Mol Biol (Noisy-le-grand) 2016;62:44-7.

21. Pappa KI, Gazouli M, Anastasiou E, Loutradis D, Anagnou NP. The Q192R polymorphism of the paraoxonase-1 (PON1) gene is associated with susceptibility to gestational diabetes mellitus in the Greek population. Gynecol Endocrinol 2017;33:617-20.

22. Ibrahim AA, El-Lebedy D, Ashmawy I, Hady MA. Association between paraoxonase-1 gene Q192R and L55M polymorphisms in systemic lupus 
erythematosus (SLE) and anti-phospholipid syndrome (APS) in a population from Cairo of Egypt. Clin Rheumatol 2017;36:1305-10.

23. Turgut Cosan D, Colak E, Saydam F, et al. Association of paraoxonase 1 (PON1) gene polymorphisms and concentration with essential hypertension. Clin Exp Hypertens 2016;38:602-7.

24. Turan M, Ucler R, Aslan M, et al. Serum paraoxonase and arylesterase activities in patients with chronic otitis media. Redox Rep 2015;20:2415.

25. Kotur-Stevuljevic J, Spasic S, Jelic-Ivanovic Z, et al. PON1 status is influenced by oxidative stress and inflammation in coronary heart disease patients. Clin Biochem 2008;41:1067-73.
26. Shigemi H, Egashira T, Kurono Y, Mogi G. Role of superoxide dismutase in otitis media with effusion. Ann Otol Rhinol Laryngol 1998;107:32731.

27. Yariktas M, Doner F, Dogru H, Yasan H, Delibas N. The role of free oxygen radicals on the development of otitis media with effusion. Int $\mathrm{J}$ Pediatr Otorhinolaryngol 2004;68:889-94.

28. Agachan B, Yilmaz H, Karaali Z, Isbir T. Paraoxonase 55 and 192 polymorphism and its relationship to serum paraoxonase activity and serum lipids in Turkish patients with non-insulin dependent diabetes mellitus. Cell Biochem Funct 2004;22:163-8.

This is an open access article distributed under the terms of the Creative Commons Attribution-NonCommercial-NoDerivs 3.0 Unported (CC BY- NC-ND3.0) Licence (http://creativecommons.org/licenses/by-nc-nd/3.0/) which permits unrestricted noncommercial use, distribution, and reproduction in any medium, provided the original work is properly cited.

Please cite this article as: Durmuş K, Kurtulgan HK, Bora A, Yıldırım ME, Altuntaş EE. An Examination of Paraoxonase 1 Gene Polymorphism in Cases of Chronic Otitis Media. ENT Updates 2020;10(1):232-237. 